\title{
Reusable content matters: a learning object authoring tool for smart learning environments
}

\author{
Mehmet Ali Çinici ${ }^{1 *}$ (D) and Arif Altun ${ }^{2}$
}

\footnotetext{
* Correspondence: macinici@gmail. com

${ }^{1}$ Department of Computer Engineering, Nişantaşı University, Istanbul, Turkey

Full list of author information is available at the end of the article
}

\begin{abstract}
This study reports the design and evaluation process of an authoring tool that is developed for content developers and/or instructors to be able to reuse and repackage existing learning objects (LOs) according to existing instructional needs. The evaluation process included the usability and efficiency of this authoring tool with a sample group of 20 students working at the time of study through their master and/or doctoral degrees in the department of computer education and instructional technologies at a college of education. Tasks in the study included determining instructional needs, searching LOs in various repositories, and repackaging existing LOs by repurposing them. Finally, both quantitative and qualitative data were collected to assess the efficiency and the effectiveness of the tool by soliciting users' experiences. As a result of the study, it was determined that this tool is a practical content development and packaging tool for content developers and/or instructors. Suggestions concerning properties of similar authoring tools are reported and discussed as to reusability in various smart learning environments (SLE) by organizing content based on various instructional needs.

Keywords: Smart learning environments, Learning object, Authoring tools, Reusability, Instructional design
\end{abstract}

\section{Introduction}

Smart learning environments (SLEs) not only utilize a range of digital technologies in supporting learning, education and training but also provide a prominent signpost for how future learning environments might be shaped (Hoel and Mason 2018). SLEs could be seen as learning environments that are considerably improved to promote better and faster learning (Koper 2014). The driving desire behind the SLEs movement is to transform learning and instruction in productive and desirable ways. A SLE might include features to promote engagement, effectiveness and efficiency (Spector 2014). Thus, as technology continues to evolve, SLEs and the components used in these environments are receiving growing attention from the research community.

In this context, the concept of a Learning Object (LO) has attracted the attention of educators and software engineers since 1994 when it was used by Wayne Hodgins. According to various researchers, the overall purpose of developing LOs was to create 
reusable LO pools (i.e., repositories) that will serve to offer their LO collections and allow access when needed (i.e., Wiley 2006; McGreal 2004).

LOs are widely used in corporations and institutions globally with the notion of "prepared once and used many times" (Goldsmith 2007). Their most fundamental feature is their reusability. With advancements in the technology and standards movement, existing LOs could be reorganized according to changing instructional needs and extended to be used in in various contexts. However, this approach created an obstacle for both teachers and content developers: finding appropriate LOs that satisfy them, and their students' instructional needs was cumbersome and sometimes a challenging situation. Furthermore, the insufficiency of the authoring tools with the functions that allow the preparation of LOs in accordance with personalized instructional needs, their arrangement, entering their metadata, and their packaging was an undeniable fact. Wiley (2006) claimed that since LOs in their present form were not very helpful for teachers, it was time that instructional technology was put ahead of the conventional knowledge of the LO. Thus, research was needed to be redirected into understanding how instructors could reuse LOs (see, Spector et al. 2012).

It can be argued that studies on authoring tools for developing adaptive authoring tools, which help instructional designers to reuse and repackage existing LOs for their own instructional needs, are limited. In order to work with content packages easily and efficiently, Kavcic (2011) has emphasized the need for a range of tools that makes the preparation, arrangement, validation, and the play of the content packages easier. Also, in spite of the presence of a limited amount of authoring tools, authoring tools that allow the easy creation of LOs compatible with industry standards are required (Ramanathan et al. 2011). In his study, Watson (2010) suggested that teachers should be provided technical support when sharing, shuffling, reusing, and repurposing the existing LOs. In case teachers are provided with tools that allow them to create LOs with pedagogical influence without technical support, the necessity to design LOs to be reusable and modifiable will disappear.

\section{Reusability of contents for educational purposes Reusability and repurposing LOs}

Even though there is heterodoxy in the definition of a LO, there is a concept that each definition consistently emphasizes: reusability (i.e., Barrit et al. 1999; Wiley 2003; Rehak and Mason 2003; Aşkar 2003; ADL 2004; Laverde et al. 2007). Duncan (2009) has explicitly stated that reusability is an important and an inseparable component of the conceptualization of LOs.

The studies on reusability have generally focused on using the existing LOs "as they are." However, to increase the reusability of LOs, further steps might be needed. For example, when an instructor or content developer prepares a LO for a particular group of students, that LO would address the needs of that particular group but the LO might be insufficient to satisfy the instructional needs of another teacher and student group. Therefore, another instructor or content developer may need to modify that particular LO to satisfy their needs. It is observed in the literature that the existing authoring tools that will allow the partial or entire reuse of the existing LOs in accordance with the needs are limited. 
Thirdly, interoperability is an issue with LO distribution. The number of LO sources as well as the organizations that provide those LOs increase rapidly (Tzikopoulos et al. 2009). In order to ensure the interoperability of LOs, it is believed that a collaborative study among different disciplines along with education should be sought. To conclude, these problem areas emphasize the need for research in: 1) gaining benefit from the use of LOs; 2) finding the pedagogic model that would be related to better learning experiences in the development of LOs; and 3) determining what pedagogical and technical features LOs should possess in order to make reusability more purposeful. Therefore, this study aims to propose a tool to package LOs after being modified by teachers and/or professionals as content developers according to emerging instructional needs and to evaluate its effectiveness by content designers and/or instructors. Before describing the methodology, it is necessary to synthesize the existing pedagogical and technical issues in LO literature.

\section{Pedagogical issues in LOs}

Existing research on the implementation of LOs reported pedagogic insufficiencies (Mavrommatis 2008; Di Nitto et al. 2006; van Merriënboer and Boot 2005; McCormick et al. 2004); software development procedures (Zhang and Liu 2012; Sriram 2011); the role of context (Paquette 2014; Collis and Strijker 2004); platforms (Couto et al. 2013; Costa 2013; Koohang et al. 2011); copyright issues (Pegler 2011; Wiley 2007; Churchill 2005; CURVE (Centre Undertaking Research in Vocational Education) 2005); storage, reusability (Q4R (Quality for Reuse) 2014, Pegler 2011; ADL 2011; Dovrolis et al. 2009; Wiley 2007; CURVE (Centre Undertaking Research in Vocational Education) 2005; Palmer and Richardson 2004); and the roles of expertise levels (Wasim 2013; Cochrane 2007; Di Iorio et al. 2006). Moreover, pedagogic and technical qualities of content developers were emphasized in various research (Watson 2010; Laverde et al. 2007; Gunn et al. 2005). As Duncan (2009) has stated, the question that guides the discussions in the literature on LO should be changed from "What is a LO?" to "How to repurpose and reuse the existing learning content?"

The question of which pedagogic criteria LO contents should be developed is not a topic of interest for many educators (Di Nitto et al. 2006; Mavrommatis 2008). Therefore, it is important to determine the way to bring LOs together based on learning approaches and strategies (Baruque and Melo 2004). LOs can be developed in many ways. One of the two commonly used methods is to prepare ex novo an expedient LO to be compatible with a specific learning design model, while the second one is to choose the expedient LOs from the existing ones and modify them to fit the purpose (i.e., repurpose). It is emphasized that the former way which is to develop LOs ex novo may require the use of specific software to be as easy-to-use as popular word processors (Di Iorio et al. 2006). The widely-used LO development software providing this ease of use exists (i.e., Atasayar 2008) but is limited to the required technical knowledge and time to learn how to use the existing LO developing software (see, Cochrane 2007).

Several tools and technologies are used in order to prepare, modify, use/add metadata of, and reuse LOs according to specified standards (Strijker 2004), among which are 1) Authoring Tools (AT); 2) Learning Content Management Systems (LCMS); 3) Course Management Systems (CMS); and 4) Learning Management Systems (LMS). These 
authoring tools are used to provide or create LOs. According to Wasim (2013), these authoring tools can be classified according to their complexity, price, and purpose.

It is emphasized that the tool to be used for the development of LOs from scratch should be at least as easy to use as existing word processors and presentation tools ( $\mathrm{Di}$ Iorio et al. 2006). Many LO development software though fail to meet these requirements and to use the existing ones requires technical skills and time. There exist some attempts (i.e., Atasayar 2008) to develop a specific authoring tool to design and pack LOs; however, it should be noted that there is no single universally accepted standards exist yet (Fig. 1).

On the other hand, it is observed in the existing literature that researchers take different stances in describing reusability; however, they mostly agree that authoring tools, aimed partially or completely at promoting the reuse of LOs, should be in accordance with certain requirements instead of reusing them "as-is."

Within the scope of this study, the term "reusability" is defined as repurposing and modifying LOs to make them more compatible with their new context and aligned with the new instructional needs.

\section{Methods}

This study is designed as a Design and Development Research (DDR). DDR is a specific inquiry type in the area of instructional design and technology aiming at the creation of new information and validation of existing applications. Richey and Klein (2007, p. 748) defines DDR as the systematic study of design, development, and evaluation processes with the aim of establishing an empirical basis for the creation of instructional and non-instructional products and tools and new or enhanced models that govern their development.

This study has been executed in three stages. Firstly, the LO Reusability Model was developed based on a critical review of the literature, focusing mainly on the problems

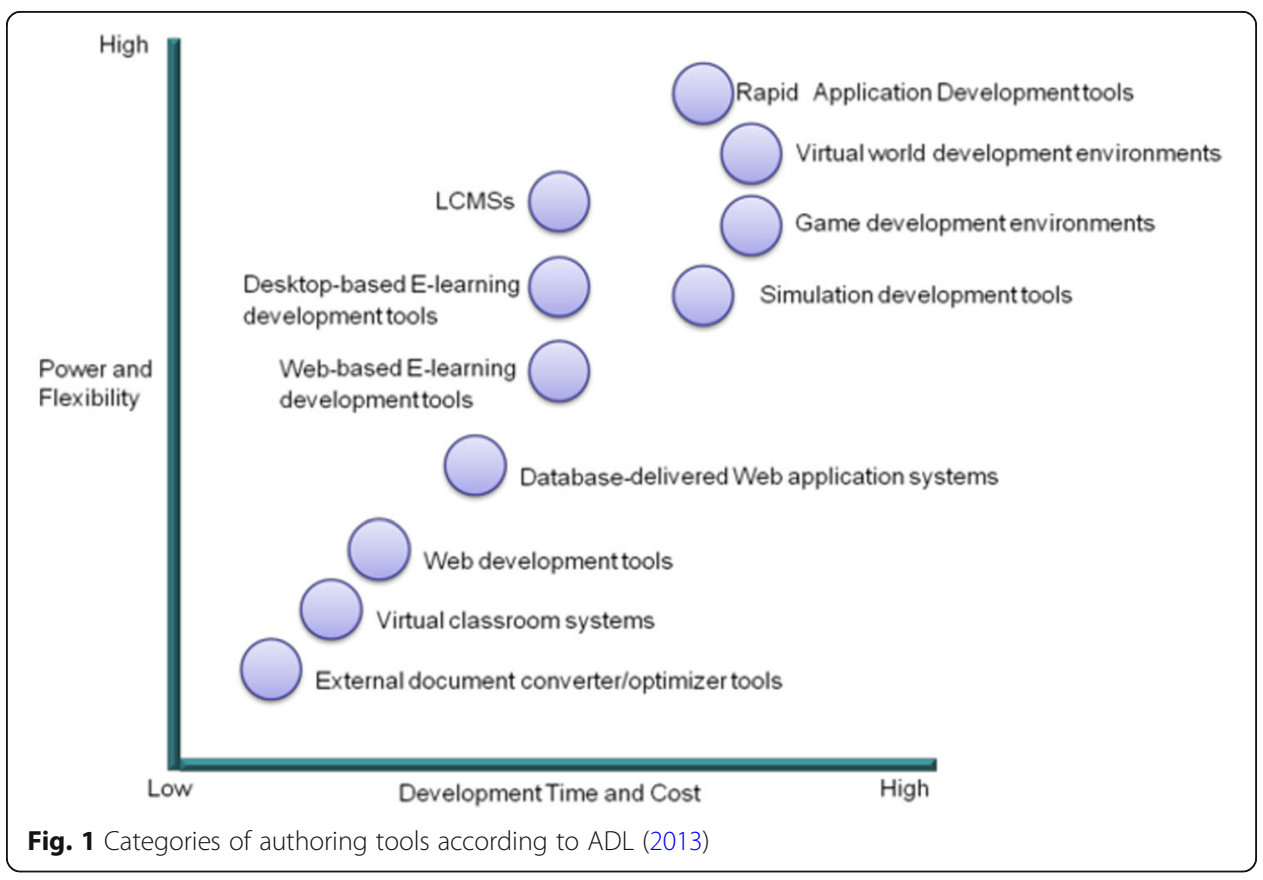


faced when reusing LOs. The review process yielded the updated metadata standards for the content when packaging LOs.

Secondly, these metadata standards were embedded into ONYA (the software tool as a product) that will serve to enable technology to solve the problems faced during the reuse of LO. This tool is designed and developed to provide users an option to modify and to repackage the existing LOs in accordance with emerging instructional needs for reuse. In order not to violate the existing copyright restrictions and licensing, we adhered to original copyright statements. If the source has open access license, users are requested to permit their consent for further use. Otherwise, they are advised about the copyright restrictions and licensing information.

Finally, an evaluation was conducted for ONYA through measurement tools and a usability test. Table 1 displays the research purposes, methods, and the expected outcomes in the study.

\section{Study setting}

The study group consisted of graduate students in computer education and instructional technology (CEIT) program at the college of education in a state funded university in Turkey. The curricula of the CEIT department included both computer programming and instructional technology related subject areas, including instructional design, human-computer interaction, learning objects, game design, and program development and evaluation. The graduate program offers masters and doctorate degrees and accepts students from various backgrounds.

\section{Participants}

The target group of the study was voluntarily selected based on criterion sampling among the graduate students attending either masters or doctorate program at the CEIT department. The criteria were set to include prior experience in knowledge and modifying LOs in accordance with instructional needs and their reuse as content developers. From a pool of 48 participants that had met the criteria, 20 participants returned with a positive feedback to participate in this study.

Table 1 Purpose of the study and methods implemented

\begin{tabular}{|c|c|c|c|}
\hline Stage & Purpose & Method & Outcome \\
\hline \multirow[t]{3}{*}{1} & \multirow{2}{*}{$\begin{array}{l}\text { Modelling Reusability of } \\
\text { LOs and Determination of } \\
\text { Metadata Standards for } \\
\text { Content }\end{array}$} & \multirow{3}{*}{$\begin{array}{l}\text { Document and Content } \\
\text { Analysis }\end{array}$} & LO Reusability Model \\
\hline & & & $\begin{array}{l}\text { LO Content Packaging and } \\
\text { Metadata Standards }\end{array}$ \\
\hline & $\begin{array}{l}\text { Conceptual Design of the } \\
\text { Tool to Be Developed }\end{array}$ & & Conceptual Model of the Tool \\
\hline 2 & $\begin{array}{l}\text { Development of the } \\
\text { Conceptually-Modeled Tool }\end{array}$ & Software Development & Learning Object Authoring Tool \\
\hline 3 & Assessment of the Tool & $\begin{array}{l}\text { Usability Measurement Tool, } \\
\text { Observation, Protocol Analysis } \\
\text { and Open-Ended Interview }\end{array}$ & $\begin{array}{l}\text { Views of Content Developers on } \\
\text { Effectiveness and Usability and } \\
\text { Determination of the Necessary } \\
\text { Features of LOs that the Authoring } \\
\text { Tools to Be Designed for Reusability } \\
\text { Should Possess }\end{array}$ \\
\hline
\end{tabular}


Demographic information (gender, age, level of education, daily computer/Internet usage, computer/Internet, and LO-content packaging experience) of the participants are shown in Table 2. Nine doctoral-level and eleven master-level students with equal gender and experience levels in LO content packaging skills participated in the study. Participants perceived themselves as intermediate- or advanced-level users of computers and the Internet, and they presented a small range with regards to daily use of computers and the Internet. All participants were provided training in learning to use the authoring tool before working on any learning activities. For a one-day training session, the participants were trained how to access LOs, what the copyright issues are, how to re-purpose them by using the tool, and how to re-submit LOs when completed.

\section{Development process of the authoring tool}

When designing the authoring tool, firstly, similar authoring tools in the literature were reviewed. The main purpose of the literature review was to determine the fundamental functions and visual features that this authoring tool should possess. Secondly, simplicity of use principle (content developers could operate the tool similar to a popular word processor) proposed by Di Iorio et al. (2006) was utilized. Finally, the Star

Table 2 Participants' demographic information

\begin{tabular}{|c|c|c|}
\hline & \multicolumn{2}{|c|}{ Participants } \\
\hline & $n$ & $\%$ \\
\hline \multicolumn{3}{|l|}{ Gender } \\
\hline Male & 10 & $50 \%$ \\
\hline Female & 10 & $50 \%$ \\
\hline \multicolumn{3}{|l|}{ Age } \\
\hline $18-25$ & 2 & $10 \%$ \\
\hline $26-36$ & 18 & $90 \%$ \\
\hline \multicolumn{3}{|c|}{ Level of education } \\
\hline Master's & 11 & $55 \%$ \\
\hline Ph.D. & 9 & $45 \%$ \\
\hline \multicolumn{3}{|c|}{ Daily computer usage } \\
\hline $3-5 h$ & 2 & $10 \%$ \\
\hline $5+$ hours & 18 & $90 \%$ \\
\hline \multicolumn{3}{|c|}{ Daily Internet usage } \\
\hline $3-5 h$ & 4 & $20 \%$ \\
\hline $5+$ hours & 16 & $80 \%$ \\
\hline \multicolumn{3}{|c|}{ Computer using experience } \\
\hline Intermediate & 5 & $25 \%$ \\
\hline Expert & 15 & $75 \%$ \\
\hline \multicolumn{3}{|c|}{ Internet using experience } \\
\hline Intermediate & 4 & $20 \%$ \\
\hline Expert & 16 & $80 \%$ \\
\hline \multicolumn{3}{|c|}{ LO content packaging experience } \\
\hline Yes & 8 & $40 \%$ \\
\hline No & 12 & $60 \%$ \\
\hline
\end{tabular}


Life-Cycle Model (Rogers et al. 1994), which was a model-driven development model, was followed as the software development model.

ONYA was developed using the Microsoft Visual Studio 2010 Ultimate (Version 4.0.30319 SP1) integrated development environment, the.NET Framework 4.0 architecture, Windows Presentation Foundation (WPF) technology, MVVM (Model-View-ViewModel) pattern, and C\# programming language as a software (WPF Ribbon Application) for Windows OS. The tool was developed by a single software developer. However, occasional support was sought from other developers when needed.

During the design and development phase, some obstacles were encountered. These challenges were informative and helpful during the development process. The first of these challenges occurred when implementing the social media components. ONYA had the social media connections available as a service. During the development of the social media interaction module to search for content when developing the software and the test processes, three different obstacles were encountered. The first one occurred when integrating a local LO repository (called EBA) hosted by the Ministry of National Education General Directorate of Innovation and Instructional Technologies. Within this social platform, teachers were offered in-house, reviewed and approved e-contents that are suitable for each grade from elementary to high school levels. During the coding process of ONYA, some changes in the technical infrastructure of the EBA were made. During the module integration test, connection to the EBA module was reengineered and redeveloped.

Secondly, a similar situation was observed with Twitter, which changed its API in June 2013. This change was reflected upon the software during the development process, as well. Lastly, the tool had an authorization problem with LORAX Web Service module, which is a Learning Object Repository Access and Exchange (LORAX) mechanism that serves the following features: QueryContent, RetrieveContent, RetrieveContentMetadata, and RetrieveContentRights. During the design phase, connection to LORAX was available as a web service. However, this policy had been changed into a location-limited web service limited to Australia. Therefore, it was decided to switch to Scootle, for which access is open with Creative Commons License. Finally, the tool had been reengineered based on those decisions and both Turkish and English language support was added. In Fig. 2, the finalized user interface of the authoring tool -ONYAis presented.

\section{An emerging model for the reusability process}

One of the main purposes of this study is to understand how existing LOs could be reused by modifying them according to varying instructional needs. The data analysis yielded some patterns which were presented in Fig. 3. This model is labeled as the LO Reusability Model (LORM).

According to LORM, the process starts with the determination of the instructional needs. Second step is to search in existing Learning Object Repositories (LOR). Once the related content packages (i.e., LOs) are found, they are extracted using the LO Authoring Tool. Using the authoring capabilities of the tool, the users can integrate their own content according to their own instructional needs., repurposed, and prepared as a new LO content package. Then, the metadata to define this new content 


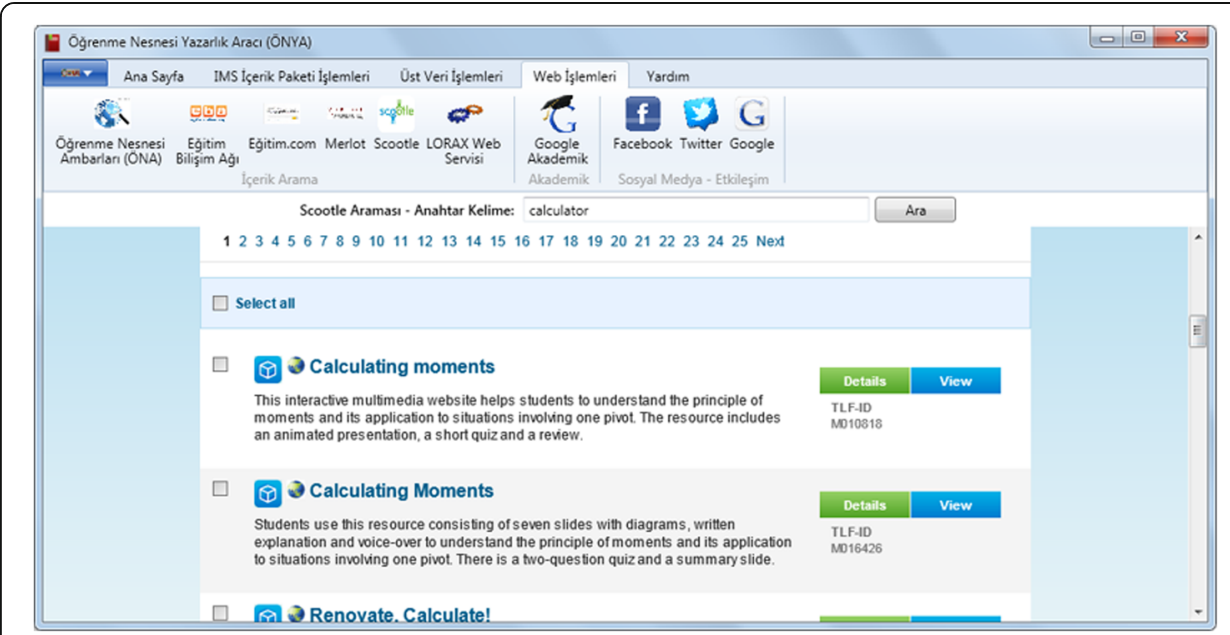

Fig. 2 The interface of authoring tool-ONYA

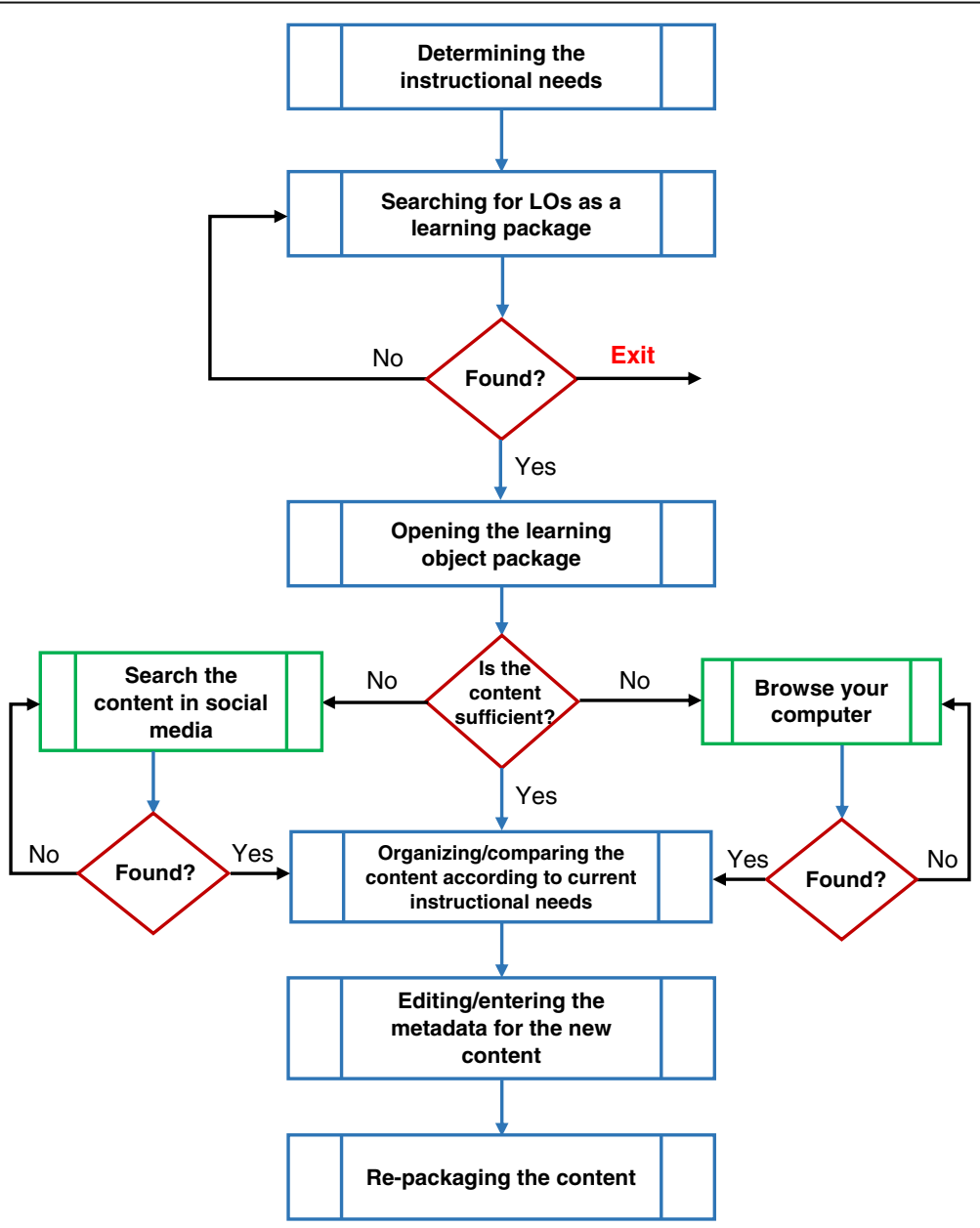

Fig. 3 Reusability model and LORM 
package is entered, and the content is packaged for reuse. In the last phase, the new content can be reused after being transferred to related LMSs and/or other systems as a content package.

When a LO is created to be used in a specific context, it is highly important to identify the metadata in order to increase its reusability. According to the IEEE LOM standards, each component of the LOM is optional. Therefore, to increase the visibility of LOs for reusability, the content editors were given an option to modify the metadata in the authoring tool along with the content of the LO itself. The suggested functionalities that facilitate the reuse of LO in this new tool are presented in Table 3.

\section{Data collection tools}

In order to evaluate the usability of the tool, firstly, a task list along with the success criteria was formed. The task list was then sent to six researchers to gather expert views on its comprehensibility and suitability. Based on the feedback received, the list was finalized. Secondly, 3-Likert Scale (Appropriate, Partially appropriate, Not appropriate) usability measurement tool, developed by Altun et al. (2009) was utilized with the researchers' permission. This measurement tool was initially developed to determine the usability of CMS with seven factors. In this study, four of the factors (Visual Sufficiency and Stability, Error Messages and Technical Sufficiency, Interface-Task Performance, and Interface-Process Performance) with a total of 27 items was used. Finally, an interview protocol was developed, with which participants' experiences regarding the use of the software were collected from each participant in one-on-one interviews. During the interviews, participants were requested to specify (a) their general opinion regarding the authoring tool (functionality, visuality, design, etc.); (b) whether they will use the tool for content packaging; (c) which three features they liked the most/least; (d) the tasks that they had difficulty in completing and their reasons; (e) the aspects of the tool that they believe that are prominent in terms of ease of use; and (f) their suggestions for improvements.

Table 3 Functions and features in ONYA

\begin{tabular}{|c|c|c|}
\hline Features & Description (Function) & Example \\
\hline $\begin{array}{l}\text { IMS Content } \\
\text { Package } \\
\text { Operations }\end{array}$ & $\begin{array}{l}\text { - Create/Open/Edit IMS } \\
\text { Content Package }\end{array}$ & $\begin{array}{l}\text { The IMS Content Package Operations menu opens the existing } \\
\text { content package for editing using the Open Content Pack } \\
\text { function. The new content package re-purposed and edited for } \\
\text { a certain educational need and uploaded to the relevant SLEs } \\
\text { for use. }\end{array}$ \\
\hline $\begin{array}{l}\text { Metadata } \\
\text { Operations }\end{array}$ & $\begin{array}{l}\text { - Create New Metadata } \\
\text { File } \\
\text { - Edit the Current } \\
\text { Metadata File } \\
\text { - Search in Metadata } \\
\text { File } \\
\text { - View Metadata File }\end{array}$ & $\begin{array}{l}\text { The metadata of the content package is edited by XML } \\
\text { Processing function. }\end{array}$ \\
\hline Web Operations & $\begin{array}{l}\text { - Search Educational } \\
\text { Content } \\
\text { - Academic Search } \\
\text { - Social Media-Interaction }\end{array}$ & $\begin{array}{l}\text { The contents could be searched on LORs (EBA, Merlot, Scootle, } \\
\text { LORAX), founded and downloaded to the system with the Web } \\
\text { Process function. When a particular LO is found, it could have } \\
\text { extracted, repackaged for a certain educational application } \\
\text { situation via IMS Content Package Operations function. }\end{array}$ \\
\hline
\end{tabular}




\section{Data collection process}

Data collection process was realized in three stages. First, the participants were provided with a predesigned scenario (task list) and were asked to complete the tasks by using the tool at their own pace. This process took about an hour and was employed according to the test stages determined by Bastien (2010) for usability studies. Meanwhile, personal observation notes were taken by the researcher synchronously. In the second stage, the participants who had completed the scenario were requested to fill in the usability measurement tool. Finally, each of the 20 participants was interviewed by the first author for 45-60 min right after the usability test. Interviews were generally held in the study rooms of the participants, or in a silent environment that is suitable for an interview. Data collection processes for all participants was completed within a week.

\section{Data processing and analysis}

Both quantitative and qualitative data were collected for the study. The quantitative data were analyzed and reported by descriptive statistics such as item averages, standard deviation, frequencies, highest/lowest, and percentages. Usability and reliability coefficients for four sub-dimensions of the scale were calculated. Then, to determine whether there was a significant difference between groups, t-tests were implemented for each sub-dimension separately. The qualitative data collected in the study were coded and analyzed with content analysis methods. The categories, as well as the repeating patterns, were determined after reading the data.

\section{Results}

\section{Evaluating the usability of the tool}

As part of the study, the participants were asked to complete the pre-designed scenario with some tasks embedded within. The completion time for these tasks was between 15 and 22:30 min with a standard deviation of $1.3 \mathrm{~min}$.

Descriptive statistics related to the ONYA and its usability results is presented in Table 4. The results yielded that the highest score was on the interface-process performance (reverse coded) and the lowest was on error messages and technical sufficiency sub-factors, indicating that the tool met the participants' expectations but needed to be improved in terms of handling the error messages. To observe whether participants' gender, level of education status (being a masters or doctorate student), perceived computer expertise level, and previous exposure to content packaging would yield a significant difference in each factor, t-tests were executed. No significant differences were observed $(p<0.05$ level). This finding can be interpreted as the participants evaluated the tool in similar ways with a homogenous approach.

Table 4 Descriptive statistics about the usability and its sub-factors

\begin{tabular}{llllll}
\hline Sub-factors & N & Mean & Standard Deviation & Min & Max \\
\hline Visual Sufficiency and Stability & 20 & 2.55 & .30 & 1 & 3 \\
Error Messages and Technical Sufficiency & 20 & 2.42 & .55 & 1 & 3 \\
Interface-Task Performance & 20 & 1.45 & .45 & 1 & 3 \\
Interface-Process Performance & 20 & 1.29 & .21 & 1 & 3 \\
\hline
\end{tabular}


In addition to the quantitative findings, participants' opinions regarding the usability of the authoring tool were determined qualitatively with eight open-ended questions.

The analysis of the data obtained from these eight open-ended questions yielded five categories and 10 themes. These categories and themes are presented in Table 5. The findings indicated that effectiveness and ease-of-use were emphasized as the most liked features whereas flexibility, error handling and recovery, and visuality were relatively less liked and/or suggested to be improved.

When the responses of the participants were examined, effectiveness emerged as the primary category. Within effectiveness, functionality of the software and interoperability both in the web environment and within itself emerged as a popular feature. Participants $1,4,14$ and 20 expressed their opinions as follows:

"It is important to be able to search in files since I may use the same document for a different project." (\#1)

"I have always used prepared packages. There is no chance of modifying these packages. Therefore, you remain restricted. With this tool, this restriction will be no more. You can create a new package using whichever part you wish to use in accordance with your own instructional needs." (\#4)

"Instead of visuality and design, functionality was given priority. It is a pretty useful and expedient tool." (\#14)

"It was so functional to provide searching in a single box in multiple repositories." (\#20)

The lack of preview feature was stated as disliked or needed to be improved. Participants 16 and 11 expressed their opinions as follows:

“The preview might be necessary.” (\#16)

"Locations and hierarchy in the main window were well-designed. However, it was hard to access the contents of the newly-opened windows." (\#11)

Table 5 Categories and related patterns

\begin{tabular}{lll}
\hline Categories & Liked & Disliked and/or Development Suggested \\
\hline Effectiveness & $\begin{array}{l}\text { Functionality (Functional. 10/10, \#20) } \\
\text { Interoperability (Web environment } \\
\text { (from inside of the program), \#12) }\end{array}$ & \\
Ease of Use & $\begin{array}{l}\text { Simplicity (Simple interface, \#14) } \\
\text { Visual Design (Ribbon menu, \#18) }\end{array}$ & \\
Flexibility & & Customisability (Language preference, \#10) \\
Error Handling and Recovery & & Guidance/Help (Debriefing, \#12) \\
& & Error Messages (Allows to make errors, \#7) \\
Appearance & Menu Structure (Button names & System Status (I would add a \\
& are chosen spot-on, \#14) & progress bar, Participant \#18) \\
\hline
\end{tabular}


Within ease-of-use, simplicity and visual design emerged as a positive feature. For example, Participants 9, 14 and 19 expressed their opinions as follows:

"It is an important feature to have the ability to fill in the metadata fields without coding knowledge. It was pretty easy to navigate through the upper tabs. I did not have difficulty in using since I was used to the user menu of Office tools such as Word, PowerPoint." (\#9)

"1. The tool is pretty plain and does not have any unnecessary details.

2. Navigation through menus is pretty easy.

3. Even people with little technical knowledge can use it.

4. I liked the tool as it is user-friendly." (\#14)

"It is simpler and less complex than the RELOAD Editor that I have used before. We are accustomed to its design. It takes a little time to package content and create metadata." (\#19)

Within flexibility, the participants did not comment on any feature that they liked while customizability was remarked as disliked and/or needed to be improved. Participants 10, 18 and 19 expressed their opinions as follows regarding this topic:

“Language option” (\#10)

"Leaving file-naming to the user" (\#18)

"The default setting of the display is full-screen, which something I am not accustomed to." (\#19)

Within error handling and recovery, the participants did not comment on any feature that they liked, and guidance/help and error messages were described as disliked and/ or needed to be improved as the tool does not show some of the necessary messages/ warnings. Participants 3 and 18 expressed their opinions as follows:

"1. Tutorial that would guide the user."

“2. An explanation regarding possible troubles in the help menu" (\#3)

"The error messages may be further tenderized." (\#18)

Within visuality, which is the last category, menu structure and system status were liked. For example, Participant 18 expressed his/her opinions regarding this topic as follows:

"Menus and submenus are prepared well and positioned sensibly. It is good that the ribbon system which I am accustomed to from Office programs is used in the menus." (\#18) 
However, a deficiency that was disliked and/or needed to be improved was identified by the participants. Participant 12 expressed his/her opinion regarding this topic as follows:

"Since the Package Content/Open features of the programs take a long time, it made me worry about the success of the operation that there is no status bar. During this process, a warning like 'Please wait, still working.' could be shown." (\#12)

\section{Discussion and conclusion}

This paper investigated the potential of an authoring tool within the context of SLEs. The focus was mainly on its functionalities that facilitated the reuse of LOs. According to Wang et al. (2007), the critical success factor is how easy it is to repurpose LOs to enable the reusability in an instructional context different from their purpose in their initial design. Even though there is a wide range of theoretical studies regarding the reusability of LOs, the number of their actual implementation is very limited. Therefore, to address this deficiency, this study is aimed at designing and implementing a LO search and repackaging software for teaching professionals and exploring the problems that arise in the reusability process after modifying the LOs to increase the effectiveness of the learning process in SLEs.

During the study, the problems that arose in the process of the reusability was determined through a DDR approach, and the LORM was proposed as a solution. As a next step, an authoring tool was developed to modify existing LOs for emerging instructional purposes. Finally, the usability of this tool was tested with a study group composed of 20 content developers and/or teachers.

Content developers and teachers had difficulty in being aware of the existing LOs, and choosing and using the most suitable product. The determined problems regarding the reusability of LOs are reported as follows:

- Human, technical, pedagogical and sociocultural factors;

- Copyright and legal issues;

- Insufficiency of metadata;

- Modifying;

- Storage, distribution, and change;

- Insufficiency of the authoring tools that possess the needed features of preparation of LOs in accordance with instructional needs and modifying metadata entry and packaging.

It is believed that authoring tools which do not require advanced skills and are easy-to-use increase the reusability of LOs. The authoring tools that are developed for solving the problems regarding the reusability of LOs would possess the following features:

- A simple interface like What You See Is What You Get (WYSIWYG);

- A user-friendly tool that possesses the main functional features but is as easy-to-use as a word processor; 
- Integration with web/social networks to search in LOR and/or on the Internet;

- Customizability;

- "Undo" feature;

- Instruction and user manual;

- Free-of-charge;

- Compatible with SCORM.

Based on the qualitative observations, it can be stated that even though teachers' and/or content developers' educational levels and computer skills are different, they would wish to modify the existing LOs in accordance with their instructional needs in different SLEs by using ONYA. Overall, they found the tool easy to use, as this will make it radically easier for them to prepare their own content.

Based on the findings, some suggestions should be addressed. Firstly, the usability analysis results suggested that the tool has some aspects that are needed to be improved further for its potential users. As in the processes of the development of other software, authoring tools regarding the reuse of LOs in SLEs require the involvement of the user in the process from the very beginning of the project.

Secondly, in line with the continuous development in the instructional technologies, it is stated that one of the technical problems that may arise in the process of the development of authoring tools is to combine the new instructional technologies in the manner to make it easier for designers, teachers, and students to develop new content. But simply using a new technology to replace prior practice may not be an effective use of an innovative technology. Because a technology is innovative does not mean that its use to support learning and instruction will be innovative or effective (Spector 2014). The only way to overcome the speed of technological improvements is to develop theoretical models and tools to estimate the quality of the designs of learning environments during or before their potential development (Graesser et al. 2008) and to recognize that an applied science enterprise such as educational research, especially as it applies to SLEs (Spector 2014). Therefore, in addition to existing authoring tools, there is a need for local and global policies that will serve to ensure comprehensive and active participation of the content developers and/or teachers in the process to ensure that these tools are used.

Thirdly, improvement areas for researchers exist. There is a need for effective search and positioning systems to be able to repurpose and reuse the existing LOs for different instructional needs and SLEs. However, it is stated that it is still hard to use the existing tools in searching for LOs, and the existing tools do not satisfy the objectives of the researchers (Najjar 2008). Implementers and/or content developers could consider how LOs could be utilized for instructional purposes.

Based on the research needs that are clearly identified in this paper, it is valuable to develop such a tool that aims to help educators to work with reusable LOs. It is a good practice to use certain theoretical frameworks to develop and test this tool. The factors that determine the reusability of a LO can be classified as structural and contextual. From the structural aspect, a LO should be self-sufficient, modular, observable, modifiable, useful, standard, and of suitable granular structure. From the contextual aspect, a LO should be generic and independent from platforms, so that the LO could be used in several contexts irrespective of any topic or discipline (Chawla et al. 2012). LOs, like 
templates, face many limitations. As the LO quality improves, its complexity level increases, becomes harder to understand, and the potential to be reused decreases (Ali 2010). The reusability of LOs can be increased by taking these matters into consideration in the very first design and development process.

\section{Abbreviations}

ADL: Advanced distributed learning; AT: Authoring tools; CEIT: Computer education and instructional technology; CMS: Course management systems; CURVE: Centre undertaking research in vocational education; DDR: Design and development research; LCMS: Learning content management systems; LMS: Learning management systems; LO: Learning object; LOR: Learning object repository; LORAX: Learning object repository access and exchange; LORM: Learning object reusability model; MWM: Model-View-ViewModel; ONYA: Learning object authoring tool (in Turkish); Q4R: Quality for reuse; RELOAD: Reusable eLearning object authoring \& delivery; SLE: Smart learning environments; WPF: Windows presentation foundation; WYSIWYG: What you see is what you get

\section{Acknowledgements}

This paper is our original unpublished work and it has not been submitted to any other journal for reviews.

\section{Availability of data and materials}

All data and material are available.

\section{Authors' contributions}

Each author contributed evenly to this paper. Both authors read and approved the final manuscript.

\section{Ethics approval and consent to participate}

This paper raises no research ethics issues.

\section{Competing interests}

The authors declare that they have no competing interests.

\section{Publisher's Note}

Springer Nature remains neutral with regard to jurisdictional claims in published maps and institutional affiliations.

\section{Author details}

${ }^{1}$ Department of Computer Engineering, Nişantaşı University, İstanbul, Turkey. ${ }^{2}$ College of Education, Hacettepe University, Ankara, Turkey.

Received: 12 June 2018 Accepted: 9 August 2018

Published online: 17 August 2018

\section{References}

ADL, SCORM 2004 4th Edition Content Aggregation Model (CAM) Version 1.1 (2004). http://www.adlnet.gov/research/scorm/ scorm-2004-4th-edition/. Accessed 4 July 2013.

ADL, SCORM Users Guide for Instructional Designers (2011). https:/www.adlnet.gov/wp-content/uploads/2011/12/SCORM_ Users_Guide_for_ISDs.pdf. Accessed 22 Mar 2012.

ADL, Choosing Authoring Tools (2013). https://www.adlnet.gov/public/uploads/ChoosingAuthoringTools.docx. Accessed 2 Dec 2017.

A Ali, Ontology-Based Model For The" Ward-round" Process in Healthcare (OMWRP), Master Thesis, Jönköping University, Sweden (2010)

A Altun, H Yurdugül, Y Gülbahar, Investigating usability constructs in a content management system. Educ. Sci. 34(152), 160173 (2009) http://search.proquest.com/openview/50bb9a17f8480e63914b150050fdc615/1?pq-origsite=gscholar\&cbl= 1056401. Accessed 9 June 2018

P. Aşkar, A new concept for educational technology: learning objects. Paper presented at the XII. Educational Sciences Congress, Antalya, Turkey (2003)

A Atasayar, Design and Usability of a Content Development Tool for Concept Teaching Process. Hacettepe University, The Institute for Graduate Studies in Science and Engineering (Master Thesis), Ankara, Turkey (2008). https:/tez.yok.gov.tr/ UlusalTezMerkezi/TezGoster?key=wBmNpkQC9Nhi90NLW7E7-ek1B5_MdXzQREcLOw3orhnMgkAt14d7KHVrSrhgXQqx. Accessed 09 July 2018.

C Barrit, D Lewis, W Wieseler, Cisco Systems Reusable Information Object Strategy: Definition, Creation Overview, and Guidelines, Version 3.0 (1999). https://www.mindmeister.com/generic_files/get_file/519411?filetype=attachment_file. Accessed 14 Dec 2017.

LB Baruque, RN Melo, Learning theory and instruction design using learning objects. J. Educ. Multimed Hypermedia 13(4), 343-370 (2004) http://search.proquest.com/openview/69c73f2e5b25471915b20b0b5e343d03/1?pq-origsite= gscholar\&cbl=34242. Accessed 1 Apr 2014

J Bastien, Usability testing: A review of some methodological and technical aspects of the method. Int. J. Med. Inform. 79(4), 18-23 (2010)

S Chawla, N Gupta, R Singla, LOQES: Model for evaluation of learning object. Int. J. Adv. Comput. Sci. Appl. 3(7), 73-79 (2012)

D Churchill, Learning object: An interactive representation and a mediating tool in a learning activity. Educ. Media Int. 42(4), 333-349 (2005) 
T Cochrane, Developing interactive multimedia learning objects using QuickTime. Comput. Hum. Behav. 23(6), 2596-2640 (2007). https://doi.org/10.1016/j.chb.2006.08.007

B Collis, A Strijker, Technology and Human Issues in Reusing Learning Objects. Journal of Interactive Media in Education. 2004(1), p.Art. 4 (2004). doi: https://doi.org/10.5334/2004-4-collis. Accessed 8 Nov 2013.

LF d Costa, Web authoring tool and repository for learning objects. Paper presented at the XVIII Congreso Argentino de Ciencias de la Computación, Corrientes (2013). http:/sedici.unlp.edu.ar/bitstream/handle/10915/32053/Documento_ completo.pdf?sequence=1. Accessed 19 Feb 2014.

P Couto, C Martins, L Faria, M Fernandes \& E Carrapatoso, PCMAT Metadata Authoring Tool. In S. G. Tzafestas (Ed.), Computational Intelligence and Decision Making, International Series on Intelligent Systems, Control, And Automation: Science And Engineering, Vol. 61, 355-363. Dordrecht: Springer (2013)

CURVE (Centre Undertaking Research in Vocational Education), The Reuse \& Versioning Guide: A Step-By-Step Manual for All Kinds of Reuse and Versioning (2005). https://web.archive.org/web/20061001223943/http://kn.open.ac.uk/public/ document.cfm?docid=1287. Accessed 6 Jan 2014.

A Di lorio, A Feliziani, S Mirri, P Salomoni, F Vitali, Automatically producing accessible learning objects. Educational Technology \& Society, 9(4), 3-16 (2006). http://www.academia.edu/download/30767092/ets_9_4.pdf\#page=8. Accessed 3 Sept 2013.

E Di Nitto, L Mainetti, M Monga, L Sbattella, R Tedesco, Supporting interoperability and reusability of learning objects: The virtual campus approach. Journal of Educational Technology \& Society, 9(2), 33-50 (2006). http://homes.dico.unimi.it/ monga/lib/vcjournal.pdf. Accessed 27 Feb 2014

N Dovrolis, ST Konstantinidis, PD Bamidis, E Kaldoudi, Depicting educational content repurposing context and inheritance. IEEE Transactions on Information Technology in Biomedicine, 15(1), 164-170 (2009). http://www.meducator.net/ dissemination.activities/files/33.pdf. Accessed 29 May 2012.

SM Duncan, Patterns of learning object reuse in the connexions repository. Doctoral Dissertation, Utah State University, Ann Arbor, US. All Graduate Theses and Dissertations, 423 (2009). https://digitalcommons.usu.edu/cgi/viewcontent.cgi?article= 1398\&context=etd. Accessed 2 May 2014.

D Goldsmith, Assessing learning objects: The importance of values, purpose and design. Academic Commons (2007). https:// web.archive.org/web/20171103205939/. http://www.academiccommons.org/assessing-learning-objects-the-importanceof-values-purpose-and-design/. Accessed 03 Nov 2017.

AC Graesser, P Chipman, BG King, in Handbook of Research on Educational Communications and Technology, ed. by M Spector, D Merrill, J van Merriënboer, M Driscoll. Computer-mediated technologies, Taylor\&Francis, New York, pp. 211-224 (2008)

C Gunn, S Woodgate, W O'Grady, Repurposing learning objects: a sustainable alternative?. ALT-J, 13(3), 189-200 (2005)

T Hoel, J Mason, Standards for smart education-towards a development framework. Smart Learning Environments, 5(1), 3 (2018)

A Kavcic, Implementing content packaging standards. InEUROCON-International Conference on Computer as a Tool (EUROCON), 2011 IEEE, pp. 1-4, IEEE (2011). http://lgm.fri.uni-lj.si/wp-content/uploads/2016/11/8326740.pdf. Accessed 21 July 2018

A Koohang, K Floyd, C Stewart, Design of an open source learning objects authoring tool-the LO creator. Interdisciplinary Journal of E-Learning and Learning Objects, 7(1), 111-123 (2011). https:/www.learntechlib.org/p/44733/article_44733.pdf. Accessed 19 Dec 2015.

R Koper, Conditions for effective smart learning environments. Smart Learning Environments, 1(1), 5 (2014)

AC Laverde, YS Cifuentes, HYR Rodríguez, Toward an instructional design model based on learning objects. Educational Technology Research and Development, 55(6), 671-681 (2007)

G Mavrommatis, Learning objects and objectives towards automatic learning construction. European Journal of Operational Research, 187(3), 1449-1458 (2008). https://doi.org/10.1016/j.ejor.2006.09.024

R McCormick, P Scrimshaw, N Li, C Clifford, CELEBRATE Evaluation Report, Version 2. The Open University, Brussels (2004).http:// celebrate.eun.org/eun.org2/eun/Include_to_content/celebrate/file/Deliverable7_2EvaluationReport02Dec04.pdf. Accessed 14 Nov 2013.

R McGreal, Online education using learning objects. RoutledgeFalmer: London and New York (2004)

J Najjar, Learning object metadata: An empirical investigation and lessons learned, Doctoral dissertation, Katholieke Universiteit Leuven, Belgium (2008). http://citeseerx.ist.psu.edu/viewdoc/download?doi=10.1.1.368.3707\&rep=rep1\&type=pdf . Accessed 11 Aug 2018

K Palmer, P Richardson, Learning object reusability-motivation, production and use. Paper presented at the 11th International Conference of the Association for Learning Technology (ALT). University of Exeter, Devon, England, pp-14-16 (2004).

G Paquette, Technology-based instructional design: Evolution and major trends. In Handbook of Research on Educational Communications and Technology, Vol.4 (pp. 661-671). Springer, New York (2014)

C Pegler, Reuse and repurposing of online digital learning resources within UK higher education: 2003-2010. Doctoral dissertation, The Open University (2011). http://oro.open.ac.uk/32317/1/Pegler_PhD_final_print_copy.pdf . Accessed 10 Aug 2018

Q4R (Quality for Reuse), Quality Assurance and Best Practices (2014). http://www.q4r.org/. Accessed 11 Aug 2014

C Ramanathan, N Gayal, M Sheth, A Pendyala, A system for managing SCORM-compliant learning objects. In Technology for Education (T4E), 2011 IEEE International Conference on (pp. 208-211). IEEE (2011) http://ieeexplore.ieee.org/stamp/stamp. jsp?Tp=\&arnumber=6004384. Accessed 4 June 2013.

D Rehak, R Mason, Keeping the learning in learning objects. Reusing online resources: A sustainable approach to e-learning, 20-34 (2003). https://www-jime.open.ac.uk/articles/10.5334/2003-1-reuse-05/galley/103/download/. Accessed 11 Aug 2018.

RC Richey, JD Klein, Research on design and development. Handbook of Research on Educational Communications and Technology, pp. 748-757, New York: Taylor\&Francis (2007)

J Preece, Y Rogers, H Sharp, D Benyon, S Holland, T Carey, Human-Computer Interaction: Concepts And Design (ICS). AddisonWesley: Reading, MA (1994).

JM Spector, Conceptualizing the emerging field of smart learning environments. Smart Learning Environments, 1(1), 2 (2014)

JM Spector, C Ohrazda, A Van Schaack, D Wiley, Innovations in Instructional Technology Essays in Honor of M. David Merrill. Routledge, New Jersey (2012)

B Sriram, Educational software development-users requirement analysis. International Journal of Computer Applications (0975-8887) Volume 31(10), 13-18 (2011). https://research.jicaonline.org/volume31/number10/pxc3875385.pdf. Accessed 9 June 2018. 
A Strijker, Reuse of Learning Objects in Context: Human and Technical Aspects. PhD dissertation, Faculty of Behavioural Sciences, University of Twente, Enschede, Netherlands (2004). https://ris.utwente.nl/ws/portalfiles/portal/6071787. Accessed 11 Aug 2017

A Tzikopoulos, N Manouselis, R Vuorikari, An overview of learning object repositories. In Learning objects for instruction: Design and evaluation (pp. 29-55). IGI Global (2009). https://pdfs.semanticscholar.org/9940/ e60f289ba279715f070fcfe64ca0e5909ac9.pdf. Accessed 11 Aug 2018.

JJ van Merriënboer, E Boot, in Innovations in Instructional Technology Essays in Honor of M. David Merrill, ed. by J M Spector, C Ohrazda, A Van Schaack, D Wiley. A holistic pedagogical view of learning objects: Future directions for reuse. Routledge, New Jersey, pp. 43-64 (2005)

C Wang, K Dickens, HC Davis, G Wills, Community Tools for Repurposing Learning Objects, European Conference on Technology Enhanced Learning (EC-TEL-2007, Crete, Greece), Springer-Verlag Berlin Heidelberg, LNCS 4753, pp. 378-392 (2007). http://eprints.soton.ac.uk/264134/1/EcTel_final.pdf. Accessed 12 Sept 2012.

J Wasim, Authoring tool: Key for e-learning system development. International Journal of Research in Commerce, IT \& Management 3(9), 128-130 (2013). http://ijrcm.org.in/download.php?name=ijrcm-4-IJRCM-4_vol-3_2013_issue-9-art-29. pdf\&path=uploaddata/ijrcm-4-IJRCM-4_vol-3_2013_issue-9-art-29.pdf . Accessed 9 June 2018.

$J$ Watson, A Case Study: Developing Learning Objects with an Explicit Learning Design. Electronic Journal of e-Learning, 8(1), 41-50 (2010)

D Wiley, Connecting learning objects to instructional design theory: A definition, a metaphor, and a taxonomy. The instructional use of learning objects, 2830(435), 1-35 (2003). http://www.reusability.org/read/ . Accessed 18 Apr 2012

D Wiley, On the sustainability of open educational resource initiatives in higher education (Paper presented at the OECD's Centre for Educational Research and Innovation (CERI) for the project on open educational resources, Paris (2006). http:// www1.oecd.org/edu/ceri/38645447.pdf. Accessed 19 Sept 2012

D Wiley, Open education license draft. Iterating toward openness (2007). http://opencontent.org/blog/archives/355. Accessed 22 Jan 2014.

H Zhang, H Liu, Educational software process improvement model and strategy. In Computer Science and Information Processing (CSIP), 2012 International Conference on (pp. 945-947), IEEE (2012). https://ieeexplore.ieee.org/abstract/ document/6309011/. Accessed 11 Aug 2018

\section{Submit your manuscript to a SpringerOpen ${ }^{\circ}$ journal and benefit from:}

- Convenient online submission

- Rigorous peer review

- Open access: articles freely available online

- High visibility within the field

- Retaining the copyright to your article

Submit your next manuscript at $\boldsymbol{\nabla}$ springeropen.com 